\title{
Passado, Presente e Perspectivas da Química no Brasil
}

\author{
AÉCIO PEREIRA CHAGAS*, MARIA APARECIDA HUGO CAGNIN** e MARCO-A. DE PAOLI***
}

\author{
Neste trabalho apresentamos um \\ resumo da história da Química no \\ Brasil, desde 1500 até os tempos \\ atuais. Procuramos relacionar os \\ desenvolvimentos da Química com os \\ fatos mais importantes da história do \\ Brasil. Em seguida discutimos a \\ situação atual da comunidade química \\ académica no Brasil do ponto de vista \\ das pesquisas e dos cursos de \\ pós-graduação. Esta seção é dividida \\ segundo as áreas de pesquisa mais \\ desenvolvidas em nosso país e tenta \\ mostrar 0 desempenho de cada uma \\ delas através dos resultados \\ apresentados nos congressos \\ nacionais. Por último discutimos as \\ perspectivas futuras de cada uma \\ destas áreas e as novas áreas de \\ pesquisa que deverão surgir em \\ decorrência destas.
}

\section{DA "DESCOBERTA" AOS TEMPOS ATUAIS}

A História da Química no Brasil ilustra bem uma tese defendida por muitos historiadores da Ciência, de que o surgimento e o desenvolvimento desta é algo engendrado e mantido pela sociedade. Se uma determinada sociedade não tem necessidade da Ciência, naquele momento histórico, ela não medrará, se a sociedade tiver, ela brotará e crescerá. Não pretendemos defender esta tese, porem apenas utilizá-la para alinhavar alguns factos marcantes da História da Química no Brasil, pois não caberia mais que isto aqui.

No período em que 0 Brasil foi colónia de Portugal (1500 a 1822), ambas as histórias se confundiram e não vamos tecer maiores comentários. Cumpre apenas destacar alguns nomes: Vicente Coelho de Seabra Silva Teles (1762-1804) [1], José Bonifácio de Andrada e Silva (1763-1838) [2] e João Manso Pereira (1750-1820) [3]. Os dois primeiros foram notáveis homens de Ciência, vivendo grande parte de suas vidas em Portugal, apesar de terem nascido deste lado do Atlântico. 0 primeiro destacou-se por seu livro "Elementos de Chimica" (1788), um dos primeiros livros de Química Moderna (o primeiro em língua portuguesa), antes mesmo do livro de Lavoisier [1]. 0 segundo, além de destacado mineralogista, teve uma grande atuação administrativa governamental em Portugal, além de Secretário Perpétuo da Academia de Lisboa. Ele é bem conhecido no Brasil como o "Patriarca da Independência", pela sua açāo política no movimento que culminou com a separação do Brasil de Portugal e em acontecimentos subsequentes. Como ministro, no novo governo aqui instalado, sua ação pela Ciência foi mínima. Manso Pereira, diferentemente dos anteriores que cursaram a universidade, foi um químico empírico, autodidata, porém com notáveis talentos.

0 cultivo e 0 interesse pela Química científica no Brasil, desde o fim do periodo colonial e até a época da $1^{a}$ Guerra Mundial, era restrito às escolas de medicina e engenharia que aqui existiam $[4,5]$. A pouca atividade industrial que aqui existia (fabricação de sabão, aguardente, etc.) era praticamente conduzida de forma empírica e nas raras vezes em que um químico profissional aqui aportava, este não deixava uma escola, isto é, não dava continuidade a seu trabalho. Nas referidas escolas de medicina e engenharia 0 ensino da Química era, na maior parte do tempo, desatualizado, transmitido de forma livresca, sem praticas de laboratório. Notáveis exceções se destacaram: João Martins Teixeira (1848-1906), com seu livro "Elementos de Chimica", um texto claro e atualizado, que teve muitas edições, e Wilhem Michler (1846-1889), conhecido químico cujo nome está associado com as cetonas aromáticas [4,5]. Michler era professor em Zürich, quando sua saúde piorou veio para o Brasil em tratamento, gostou e ficou, tornando-se professor de Quimica Orgânica na Escola Politécnica do Rio de Janeiro (1884). Montou laboratórios de ensino e pesquisas, porém pouco conseguiu produzir, falecendo em 1889 , ano em que o país deixou de ser uma monarquia e se transformou numa república (a escravidão tinha sido abolida no ano anterior). Uma outra atividade química em nosso país, também cheia de altos e baixos, foi aquela realizada por laboratórios analíticos, em sua maior parte governamentais, destinados ao controle de matérias primas e mercadorias importadas, além de minerais.

Depois da independência, na segunda metade do século XIX, planejou-se instalar uma universidade no Brasil, contando com o estímulo e o patrocinio do Imperador D. Pedro II, no entanto, as fortes oposições que se levantaram impediram a sua instalação. [6] Nesta época, os jovens brasileiros de familias abastadas iam ao exterior estudar, nāo apenas em Coimbra, mas em outros centros universitarios europeus. Jorge Tibiriçá Piratininga (1850-1928) foi um destes jovens [4,5]. Estudou Química em Zürich, doutorou-se (1879) com uma tese em que estudava a reação do monóxido de carbono com hidróxido de sódio, produzindo formiato de sódio (esta reação é até hoje utilizada industrialmente para a produção de formiato). Ao regressar ao Brasil, assim como José Bonifácio, enveredou-se pela política chegando a tornar-se Presidente da então Província de São Paulo.

Um campo de pesquisas que começou a se desenvolver no Brasil, já na época imperial, foi a Fitoquímica. Dentre os pioneiros destaca-se a figura de Theodor Peckoldt (1822-1912), farmacêutico alemão que se radicou no Brasil e produziu uma extensa obra, sendo posteriormente continuada por discipulos, inclusive seu próprio filho $[4,5]$. Esta é uma exceção, que acaba por confirmar a tese inicial.

Por ocasião da $1^{\text {a }}$ Guerra Mundial, o bloqueio naval inglês privou o país de matérias-primas químicas, em sua maioria importadas da Alemanha. Nesta época começou a funcionar no Brasil a primeira fábrica de ácido sulfúrico, próxima a São Paulo [4,5]. Também neste período, iniciou-se uma campanha pública: "Façamos químicos", através da imprensa e nas tribunas políticas. A campanha, apesar das oposições, surtiu 
efeito e em 1920 são criadas no Brasil nove escolas técnicas superiores de Química Indus-trial $[4,5]$. Estas escolas, espalhadas pelo pais (Belém do Pará, Recife, Salvador, Ouro Preto, Belo Horizonte, Rio de Janeiro, São Paulo, Curitiba e Porto Alegre), começaram a funcionar de forma precária. Em algumas conseguiu-se contratar professores qualificados, do exterior, e em outras utilizouse pessoal improvisado. De qualquer modo, foi o início do ensino da Química profissional no Brasil. Por volta de 1930 , estimou-se em trezentos o número de profissionais formados, porém apenas metade exercia a profissão. De qualquer forma, a sociedade brasileira, ao ensaiar 0 seu primeiro surto industrial, necessitou de químicos.

Em 1934, dois anos depois que as tropas paulistas foram derrotadas no final da "Revolução Constitucionalista de 32", fundou-se a Universidade de São Paulo, cujo principal núcleo universitário era a Faculdade de Filosofia, Ciências e Letras $[4,5,7]$. Foram contratados na Europa professores capacitados em diversas áreas (Matemática, Fisica, Química, Botânica, etc. ) e iniciou-se a pesquisa científica no Brasil, de forma académica. Na mesma época foi criada no Rio de Janeiro a Escola Nacional de Química, como uma metamorfose da antiga escola de Química Industrial, que daria ao ensino uma orientação científica em lugar da orientação técnica anterior.

A fundação da Universidade de São Paulo, além de marcar realmente 0 início da atividade cientifica, mostra também 0 interesse de parte da sociedade pela mesma. Pouco depois fundou-se a Universidade do Distrito Federal, depois absorvida pela Universidade do Brasil, no Rio de Janeiro 7. Nesta época, que antecede 0 inicio da $2^{\mathrm{a}}$ Guerra Mundial, iniciou-se um surto de industrialização do país, em parte motivado pelas dificuldades do comércio exterior. Também aportaram ao Brasil, devido à ascensão do nazismo no continente europeu, muitos intelectuais de origem europeia (boa parte de origem judaica), que influenciaram em muito o ambiente cultural do país.

Após o fim da $2^{a}$ Guerra Mundial continua 0 crescimento industrial do país, e na década de 50 , muitas escolas de Química Industrial transformam-se em Escolas de Engenharia Química [5]. A procura de químicos foi sempre maior que a oferta, entretanto, o desenvolvi- mento científico não acompanhou o desenvolvimento industrial. As fábricas que se montaram no Brasil utilizaram sempre instalações e tecnologias importadas e a pesquisa acabou sempre atuando apenas como uma formadora de pessoal.

Na década de 60 , além do surto industrial pelo qual o pais passou, a pressão populacional obrigou o governo a uma rápida expansão do sistema de ensino, em todos os niveis, o que foi feito com sacrifício da qualidade. Novas universidades foram criadas, assim como cursos de Química. A tradição em pesquisa na Química de Produtos Naturais permitiu a criação, em 1963, do primeiro curso de pós-graduação no actual Centro de Pesquisa em Química de Produtos Naturais da Universidade Federal do Rio de Janeiro. Nos governos militares, houve uma certa pressão para que se inciasse a criação de programas de pós graduação nos moldes norte-americanos. Apesar da forma como esta criação foi conduzida, isto contribuiu decisivamente para o desenvolvimento da Química. Nesta época (1964 a 1986), também consolidou-se 0 parque petroquímico nacional, construido com tecnologia importada, sem a participação dos químicos nacionais.

No caso da Química, os novos cursos de pós-graduação implantados a partir de 1988 propiciaram uma tênue descentralização da pesquisa. Na atualidade, dos 21 Programas de Doutorado, 16 localizam-se no Sudeste, 3 no Nordeste, 1 no Centro-Oeste e 1 no Sul do país. No que diz respeito aos atuais 38 Programas de Mestrado, há 2 que são desenvolvidos no Norte, 7 no Nordeste, 23 no Sudeste, 5 no Sul e 1 no CentroOeste [8]. 0 desenvolvimento desigual das regiōes brasileiras, dos pontos de vista sócio-económico e cultural, afeta, consequentemente, as atividades de pósgraduação. No Sudeste encontram-se os mais antigos curso de pós-graduação do país e também concentra-se 0 maior número de cursos em nivel de excelencia, em todas as áreas do conhecimento.

Em 1977 fundou-se a Sociedade Brasileira de Química (SBQ), visto que a associação então existente já não correspondia aos interesses da comunidade. Com a fundação da SBQ, criou-se também a revista Química Nova, que, pela sua penetração entre estudantes dos vários niveis, trouxe um redobrado interesse pela Química. Hoje esta revista é bimensal com uma tiragem de 5.000 exemplares. Com o tempo houve a necessidade de um outro periódico, com abrangência a nível internacional, sendo criado o Journal of the Brazilian Chemical Society com um corpo editorial internacional e artigos em inglês. A assinatura deste periódico é vendida na América do Norte e Ásia pela American Chemical Society. Atualmente, a SBQ organiza as atividades científicas através de suas divisōes. Um número sempre crescente de químicos comparece à Reunião Anual da SBQ. Á ultima destas, a $17^{a}$, em Maio de 1994, compareceram cerca de 1550 sócios, entre estudantes de química de graduação e pós-graduação, professores, pesquisadores e um pequeno número de profissionais de empresas. Foram apresentadas 1171 comunicações, que haviam passado por um processo de arbitragem ( $6 \%$ das comunicações submetidas foram recusadas). Estes trabaIhos ficaram assim distribuidos: Ensino de Quimica 60, Eletroquímica e Eletroanalítica 70, Físico-Química 82, Fotoquimica 31, Produtos Naturais 127, Química Ambiental 76, Quimica Analítica 147. Química Biológica 14, Química Inorgânica 196, Química dos Materiais 84, Quimica de Superfície e Colóides 22, Química Tecnológica 25, Química Teórica 24, Estrutura Química-Atividade Biológica 22 e Quimica Orgânica 191. Atualmente, uma das principais metas da SBQ é penetrar nas industrias quimicas brasileiras promovendo a integração da academia com o setor produtivo. Acordos internacionais garantem aos sócios da SBQ a participação nas actividades de suas congêneres em Portugal, França e Estados Unidos.

$\mathrm{Na}$ segunda metade da década de 80 começou-se a ensaiar um novo impulso da indústria química nacional com a expansão do parque industrial de produtos químicos finos. Parecia que, nesta etapa, a participação dos químicos no desenvolvimento industrial seria agora mais direta e visível, mas a recessão económica desencadeada pelo governo Collor (1990) sustou os empreendimentos e incentivos. Parece que esta fase, felizmente, está passando.

A vontade expressa dos pesquisadores de inserir, no contexto da pesquisa fundamental, articulações tecnológicas e sociais encontra, na atualidade, condições favoráveis na burocracia universitária, devido à existência de instrumentos legais viabilizadores da prestação de 
consultoria ao sector produtivo. No âmbito do país existem instrumentos específicos de apoio financeiro como 0 Programa de Apoio ao Desenvolvimento Científico e Tecnológico (PADCT) e o Programa de Formação de Recursos Humanos em Áreas Estratégicas (RHAE). Há também a recente lei de incentivos fiscais à Ciência e Tecnologia, que permite às empresas nacionais utilizarem parte das taxas federais em investimento de pesquisa e desenvolvimento. Apesar destes incentivos, as baixas rentabilidade e competividade das empresas nacionais (devido ao mercado interno restrito) associada à visão imediatista do empresário, geram, na maioria dos casos, pouco interesse em investir na pesquisa, acarretando uma crescente fragilidade tecnológica ao pais.

\section{PANORAMA ACTUAL E PERSPECTIVAS}

Nesta seção apresentamos um panorama sintético do estágio atual da pesquisa e da pós-graduação em Química no Brasil bem como as perspectivas da pesquisa académica nas tradicionais sub-áreas da Química, a partir, sobretudo, de avaliações e percepções advindas de pesquisadores com expressiva atuação científica manifestadas em questionário abrangente distribuido pela Sociedade Brasileira de Química entre os membros da comunidade quimica [9]. A divisão desta seção nas quatro áreas tradicionais da Química se deve apenas à necessidade de organizar o texto, não representando uma compartimentalização artificial do conhecimento.

\section{Química Orgânica}

A Quimica Orgânica é a sub-área que detém 0 maior número de pesquisadores, a mais extensa disseminação de grupos de pesquisa no pais, bem como a mais alta produção científica formal, que é disseminada em revistas de circulação internacional [10]. Há 12 anos se realizam os "Brazilian Meeting on Organic Synthesis", reunindo parte da comunidade dos quimicos orgânicos. No último evento, realizado em Campinas, em 1992, participaram 330 químicos brasileiros apresentando 135 comunicações [11]. Houveram também conferências proferidas por pesquisadores estrangeiros convidados. Os químicos de produtos naturais não realizam o seu próprio congresso, preferindo apresentar os seus trabalhos nas Reuniões Anuais da $S B Q$. No entanto, recentemente foi criada a Divisão de Produtos Naturais da SBQ.

A Química de Produtos Naturais é a especialidade com maior tradição de pesquisa no país, notadamente na Fitoquimica. A nivel mundial, a Química de Produtos Naturais foi a base dos primeiros avanços na Química de Corantes. Pesticidas e Medicamentos (sendo a indústria química da época directamente associada ao trabalho acadêmico [12]). No futuro, esta área continuará a ter repercussões profundas no sector industrial pelo fato de envolver substâncias naturais e intrinsicamente não mutagênicas, cuja identificação vem sendo acelerada e facilitada pelo desenvolvimento de técnicas analiticas cada vez mais sofisticadas, precisas e rápidas.

A busca de moléculas bioativas de plantas e de animais, incluídos os aquáti$\cos$, constitui um campo vasto e promissor da Química de Produtos Naturais. 0 Brasil, com sua imensa biodiversidade e experiência de pesquisa acumulada, poderá transformar esta especialidade em um efetivo agente portador de futuro, caso consiga vencer as barreiras existentes ao seu desenvolvimento que são comuns às demais especialidades.

A Química Orgânica Sintética e a Físico-Química-Orgânica são especialidades de desenvolvimento mais recente no país. Seu marco inicial foi a criação do Departamento de Química da Universidade de São Paulo (USP), em 1934, e seu progresso nos últimos anos é expressivo.

A Química Orgânica Sintética é bem desenvolvida na região CentroOeste (Brasilia) e no Sudeste (Rio de Janeiro e Estado de São Paulo). Há uma clara e generalizada preocupação dos pesquisadores desta especialidade em estimular o seu progresso, quer do ponto de vista da pesquisa fundamental (como 0 estudo de sinteses totais e parciais de inúmeras classes de substâncias, incluindo as de origem natural que apresentam actividade biológica potencial; o desenvolvimento de novos métodos sintéticos e a aplicação de métodos de sintese na preparação de compostos bioativos), quer relativamente aos seus aspectos mais aplicados, através do desenvolvimento de sinteses de produtos orientados para a Química Fina, explorando a utilização de matérias-primas que sejam produtos naturais abundantes.
Há uma predisposição dos químicos orgânicos sintéticos em contribuir com o desenvolvimento do setor industrial de Química Fina, altamente desnacionalizado (em cerca de $75-80 \%$ ) e de importância estratégica, posto que é supridor vital de vários segmentos industriais de ponta, como 0 de defensivos agricolas, de alimentos e de medicamentos [15]. Na Química Orgânica Sintética, a sintese de substâncias naturais é considerada de futuro altamente promissor posto que, além dessas substâncias terem, muitas vezes, aplicação economica direta, são, também, pontos de partida para a obtenção de novas moléculas mais estáveis e mais especificas para uso agricola e farmacológico. Sob uma óptica mais abrangente, independentemente da origem da matéria prima, a síntese orgânica "permanecerá como a tecnologia mais importante na manufatura de drogas" [24] ou medicamentos, para a qual assume relevância especial a busca de processos de mais baixo custo que levem em conta, também, a segurança e a preservação do meio ambiente.

A Fisico-Química-Orgânica é bem desenvolvida no Sul do pais (com maior ênfase no estudo de reacções micelares) e no Sudeste (investigação de mecanismos de reações orgânicas em geral) com algumas interações com grupos de pesquisa dos paises do "cone-sul" (Argentina, Uruguai e Paraguai). No Norte, Nordeste e Centro-Oeste as actividades de pesquisa nesta especialidade são pouco expressivas. Uma conferência brasileira de Fisico-Química Orgânica é organizada periodicamente por quimicos da Universidade Federal de Santa Catarina, Florianópolis, desde 1982, publicando-se 0 periódico "Atualidades em Fisico-Química-Orgânica".

Uma área da orgânica que é bastante interdisciplinar e que se encontra razoavelmente desenvolvida na região Sudeste é a Fotoquímica. Há grupos usando-a como ferramenta experimental para sintese de novos compostos e grupos que estudam os processos fotoquímicos e fotofísicos. Estes últimos se confundem com os grupos da sub-área de físico-química. Esta área de pesquisa começou no Brasil na década de 70 , com a vinda de pesquisadores norte-americanos dentro do programa de intercâmbio entre a National Academy of Sciences e o Conselho Nacional de Pesquisas. Hoje ela está diversificada entre químicos orgânicos, inorgânicos, fisico-químicos e 
químicos ambientais. Desde 1979 se realizam os Encontros Informais de Fotoquímica e Fotobiologia, com a participação de quimicos e bioquímicos. Mais recentemente estas reuniōes passaram a ser organizadas pela Divisão de Fotoquímica da SBQ.

\section{Química Inorgânica}

As condições para a pesquisa em Química Inorgânica no pais surgiram com a criação da USP e a vinda do professor Heinrich Rheinboldt interessado, entre outros campos, na Química de Compostos de Coordenação. Esta subárea ganhou consistência em 1960 , quando se implantaram as linhas de pesquisa em Química de Coordenaçāo de Lantanídeos [9]. A Química de Compostos Lantanídicos disseminou-se no país a partir dos químicos pós-graduados na USP. Hoje, ela já se ampliou, abrangendo os estudos de ions lantanídicos em sistemas cristalinos e amorfos, sinterização e caracterização de vidros e vitrocerâmicas. Deve-se ressaltar que uma empresa brasileira, a Orquima, era detentora de diversas patentes internacionais de processos de extração e purificação de sais de lantanídeos provenientes da areia monazítica. Com a encampação desta empresa pelos governos militares estas patentes foram perdidas.

Outro salto qualitativo resultou do programa conjunto Conselho Nacional de Pesquisas e Academia Nacional de Ciências dos Estados Unidos (CMq/NAS), vigente no período 1969/1976. Este programa possibilitou a criação de novos grupos de pesquisa em química inorgânica e orgânica. Deve-se ressaltar que este programa visava desenvolver todas as sub-áreas da química, no entanto, os objectivos foram alcançados de forma satisfiatória somente na quimica de compostos de coordenação e na fotoquímica orgânica. Na sub-área de inorgânica 0 programa CNPq/NAS lançou as bases para a interligação entre a química de coordenação tradicional e os compostos com organização supra-molecular.

A expansão nas linhas de pesquisa em Inorgânica, nos últimos nove anos, não é generalizada, concentrando-se na Química de Coordenação, Cinética e Mecanismos de Reação de Complexos Inorgânicos e na Quimica de Compostos Organo-Metálicos [13]. Ainda no contexto da química de coordenação, um campo de actividades com característi- cas multidisciplinares é o estudo dos chamados adutos ou complexos moleculares. Esta linha de pesquisas foi introduzida no Brasil por Heinnch Rheinboldt em 1934 e tem sido desenvolvida em várias instituições brasileiras [14].

Esta sub-área sofreu uma grande diversifiçāo nos últimos anos, como se pode ver nos resumos dos trabalhos apresentados no VII Simpósio Nacional de Química Inorgânica, realizado em Caxambu em 1994. Surgiram trabalhos com zeolitas, compostos de intercalação, materiais suportados, "clusters", etc.. Apesar de inúmeros problemas tecnológicos tradicionais e de ponta estarem ligados a Química Inorgânica (metais, ligas, catalisadores, materiais supercondutores, semicondutores, cerâmicas odontológicas,etc.), parece haver pouca motivação entre 0 restrito número de pesquisadores da sub-área para enveredar por esses rumos e para interagir com físicos e biólogos. Uma exceção está na Universidade Estadual de Campinas, onde há um grande grupo se dedicando a um programa denominado "Química para a Eletronica", onde se desenvolvem pesquisas em vidros, semicondutores e precursores para MOCVD (deposição de cristais por decomposição de compostos organo-metálicos).

Há no Brasil uma grande falta de sintonia entre a universidade e a indústria, 0 que pode ser sentido mais profundamente no campo da Catálise [11]. A universidade está apta e predisposta a aprofundar 0 estudo de catalisadores homogeneos e de catalisadores suportados, que são fundamentais na manufatura de produtos de alto valor agregado como os de Quimica Fina. No entanto, prevalece na indústria a Catalise Heterogênea, como reflexo do estágio de desenvolvimento indústrial brasileiro. 0 empresário brasileiro resiste a usar uma tecnologia moderna, a Química Fina, fundamentada em um maior conhecimento científico.

A evasão de divisas do país no setor de Química Fina é indicador das causas de seu baixo nivel de desenvolvimento endógeno [15]. No caso dos catalisadores industriais, estes acabam sendo importados pela indústria instalada no país, sob a forma de pacotes tecnológicos fechados [16]. A dependência das importações è profunda, posto que mais de $95 \%$ dos produtos químicos passam por vários processos catalíticos, evidenciando 0 alto valor estratégico deste campo de pesquisa. A Catálise é um exemplo clássico de agente portador de futuro para o desenvolvimento do pais, hoje condicionado a injunções de mercado. Esse quadro é inibidor da pesquisa acadêmica e do desenvolvimento social, a despeito de condições internas altamente favoráveis à disseminação e apropriaçāo da pesquisa nesta especialidade. Dentre os setores mais diretamente condicionados ao desenvolvimento da Catálise no pais, merecem citaçāo especial a álcooquímica e a redução da poluição ambiental.

Em nível mundial, é no âmbito da Catálise que se situa uma interface particularmente ativa da pesquisa de fronteira da Química, que é a crescente influência da Química Inorgânica na Química Orgânica Sintética. Um exemplo dessa interface é o desenvolvimento de catalisadores de metais de transição para reações de ciclização químio, régio e estéreo-seletivas, onde a importância fundamental é a especialização dos sistemas vivos neste tipo de controle [17].

No pais, a Catálise é vista pelos químicos inorgânicos como uma oportunidade de renovação da pesquisa que, para avançar em direcções mais proficuas, exige uma maior interação com os químicos orgânicos [18]. 0 espaço institucional para essa interação e para o desenvolvimento da Catálise existe: o Programa Nacional de Catálise (PROCAT). Este programa, hoje independente, foi iniciado por ação estabelecida no âmbito do Programa Nacional de Apoio a Química (PRONAQ, criado pelo CNPq em 1980. O PRONAQ. similarmente ao Programa CNPq/NAS, objectivava fortalecer 0 setor químico via geração e absorção da Ciência e da Tecnologia pela Indústria Química Nacional. Sua extinção coincidiu com 0 estabelecimento do PADCT, que absorveu, na forma de subprogramas, várias das acçōes pretendidas pelo PRONAQ: a criação de um sistema eficiente de manutenção de equipamentos; a capacitação tecnológica, incluindo as áreas de pesquisa, indústria e comércio no sector de instrumentação e o provimento de insumos essenciais aos laboratórios de ensino, pesquisa e desenvolvimento.

\section{Química Analítica}

A Química Analítica é uma das sub-áreas mais tradicionais da Química no Brasil. Apesar disso, ela comporta a menor produção científica nos anos 70 (disseminada principalmente em revistas 
nacionais), o menor contingente de pesquisadores contemplados com as bolsas pelo $\mathrm{CMq}$, nas décadas de 70 e 80 , além de vir disputando com a Química Inorgânica a menor parcela de recursos do Programa de Auxilios à Pesquisa do $\mathrm{CNPq}$ dirigidos à Química.

Há 12 anos vem se realizando bienalmente os "Encontro Nacional de Química Analítica", ENQA, organizado pela Divisão de Química Analítica da SBQ. 0 último ENQA, realizado no Rio de Janeiro em 1993, reuniu 400 participantes que apresentaram 344 trabalhos nos seguintes assuntos: análise por injeção de fluxo, espectroanalítica, análise orgânica, metodologia, eletroanalítica e química analítica ambiental. Isto mostra uma revitalização desta sub-área.

A especialidade da Química Analítica com actividades de pesquisa mais pronunciadas e a Química Analítica Orgânica e Inorgânica, particularmente no campo do Desenvolvimento de Métodos de Separação, Detecção e Determinação de Constituintes Químicos. Merece destaque a aplicação das seguintes técnicas: eletro-analíticas, de absorção e emissão atómicas por plasma, termo-analíticas e radioquímicas. Tais pesquisas concentram-se no Sudeste (São Paulo, Minas Gerais e Rio de Janeiro), Nordeste (Bahia) e Centro-Oeste (Brasilia). Cita-se, ainda, as pesquisas em Geoquímica Orgânica, restritas ao Rio de Janeiro. Todas as demais especialidades são consideradas pouco desenvolvidas, carecendo de estimulos específicos, tanto a Química Ambiental quanto a Instrumentação/Automação Analítica.

No Brasil a Química Analítica se confunde com a Química Analítica. Apesar desta visão ser altamente equivocada, ela contribuiu para que se desenvolvessem métodos e instrumentação para os estudos da atmosfera, especialmente dos aerossóis resultantes da poluição urbana.

No que concerne à pesquisa em Instrumentação/Automação, há poucas empresas nacionais dedicadas à fabricação de instrumentos analíticos, que é restrita aos relativamente simples e com significativo grau de obsolescência em relação ao mercado internacional. Mesmo assim, estes equipamentos não são competitivos em termos de preço com os importados. 0 citado Subprograma de Instrumentação do PADCT objetiva ampliar o desenvolvimento nacional neste setor. Entretanto, seu impacto só poderá ser devidamente aquilatado a médio prazo. Porém, é digno de nota, o desenvolvimento, pelo grupo do Centro de Energia Nuclear na Agricultura/USP, de técnicas de injecção por fluxo contínuo, atualmente disseminadas em vários outros centros de pesquisa nacionais.

\section{Físico-Química}

No âmbito da Química, as pesquisas físico-quimicas só começaram a ser desenvolvidas em 1944 - dez anos depois de seu inicio no Departamento de Física da USP, que abrigou os químicos interessados em estudos de espectroscopia [19].

A Físico-Química traz em sua génese a interdisciplinaridade, da qual depende cada vez mais o vigor dessa sub-área. 0 seu progresso no país foi um dos mais expressivos durante os anos 70 , tendo contado, para tanto, com a participação dos físicos [20]. Apesar dos físico-químicos de origem Química delimitarem suas atcividades de pesquisa em campos diferentes daqueles com formação na área da Física, a Espectroscopia (especialidade detentora do maior número de publicações na sub-área, nas décadas de 70 e 80) mostrava-se como campo de interesse comum. Ressalta-se que 0 nascimento na Inglaterra desta especialidlade, no século passado, só foi possivel devido ao trabalho colaborativo de quimicos e físicos [21].

A especialidade mais desenvolvida da sub-área é a eletroquímica, cujas atividades de pesquisa estão principalmente concentradas em São Carlos, Estado de São Paulo. Este desenvolvimento se deu, principalmente, depois da imigração de eletroquímicos argentinos para aquela região do país. Em outras regiōes também há grupos de pesquisa em eletroquímica e corrosão em Institutos de Química e em Faculdades de Engenharia Química. Apesar do seu interesse industrial, a sintese orgânica por via eletroquímica é pouco pesquisada, com a exceção de um grupo em São Paulo. A pesquisa em síntese e caracterização eletroquímica dos polímeros condutores intrínsecos eletrônicos e iônicos se disseminou recentemente e está localizada em Campinas, São Carlos, Recife, Belo Horizonte e Porto Alegre. Deve-se lembrar que os "Simpósios Brasileiros de Eletroquímica e Eletroanalítica" vêm sendo realizados há 18 anos. 0 ültimo. realizado em Abril de 1994 juntamente com o Congresso Iberoamericano de
Eletroquimica, reuniu 300 pesquisadores apresentando 250 trabalhos.

A segunda especialidade considerada de reconhecida competência (provavelmente, não só do ponto de vista dos que a vêem como campo de pesquisa, mas também dos que são seus usuários) é a Espectroscopia, especialmente no Sudeste (Rio de Janeiro e São Paulo), regiões onde as Espectroscopias de Massa, Eletrônica, Vibracional, Ressonância Nuclear Magnética (RMN), por Impacto de Elétrons e Multifotônica são avançadas, e no Nordeste (Pernambuco), onde as Espectroscópias por Impacto de Elétrons, Ótica Linear e Não Linear são desenvolvidas.

As pesquisas em Espectroscopia, bem como 0 uso de técnicas espectroscópicas por outras linhas de pesquisa, necessitam, para o seu aprimoramento, de instrumentos avançados e sofisticados, visando não só ao aperfeiçoamento das espectroscopias citadas, como também a disseminação e vulgarização de uso ainda restrito, como a Ressonância Paramagnética Electrónica (EPR), a de laser de alta resolução e a em feixes supersônicos, por exemplo [22]. Devese ressaltar a construção do Laboratório Nacional de Luz Sincrotron nas vizinhanças da Universidade de Campinas, que permitirá aos químicos 0 acesso a estas técnicas espectroscópicas modernas.

A terceira especialidade a considerar é a Físico-Química Teórica (destacando-se aqui Panambuco, São Paulo, Minas Gerais e, em menor grau, Rio de Janeiro e Brasilia). Há um contingente de pessoal qualificado que permite 0 avanço da Química Computacional (Química Quântica, Quimiometria e Dinâmica Molecular) e das suas aplicações interdisciplinares (na Química Orgânica e na Farmacologia, por exemplo). Hoje em dia, os químicos teóricos são os maiores usuários de computação de alto desempenho no país. A perspectiva no âmbito dessa especialidade é de que, a incorporação rotineira da computação em grande escala em programas experimentais afete a forma como a própria Química vem sendo praticada. Desde 1981 que vêm se realizando regularmente os Simpósios Brasileiros de Química Teórica. 0 último ocorreu em Novembro de 1993 em Caxambu, reunindo 235 participantes com a apresentação de 190 trabalhos. Os trabalhos completos destes simpósios são publicados no J. Molecular Structure. 
As demais especialidades existem, mas são menos desenvolvidas. Cita-se, como exemplo na Química de Superfície e Colóides, 0 estudo de Micelas e de Fenômenos de Superfície (fundamentais para o progresso da Química Macromolecular, do Estado Sólido e da Catálise); na Química do Cristal, o estudo de Cristais Líquidos e da Cristalografia por Difração de Raios-X; na Termodinâmica/Termoquímica, 0 estudo Termodinâmico de Compostos de Coordenação de Processos Irreversíveis e Métodos Termoquímicos.

\section{Outras Sub-áreas da Química e a Interdisciplinaridade}

A visão do químico brasileiro sobre as perspectivas de seu trabalho científico está em fase de mutação. Nota-se que uma maior prioridade vem sendo dada ao desenvolvimento da Química de Novos Materiais. 0 progresso dessa especialidade exige a integração de cientistas com diferentes formações em um grupo comum de pesquisa. Isto já começa a ocorrer no pais, mais destacadamente no Estado de São Paulo [23]. A Química de Materiais é considerada como a mais importante dentre os principais temas científicos que levarão no futuro a união de áreas de pesquisa [24]. Nesta direcção há grupos que se dedicam a fotoeletroquímica, a química dos semi-condutores e a química dos polimeros.

A química dos polímeros representa um capítulo à parte nesta história, pois a pesquisa nesta área se iniciou nas universidades muitos anos depois que as grandes indústrias já se haviam instalado no país. Começou no Rio de Janeiro com o Instituto de Macromoléculas, na década de setenta, e se disseminou por todo o país. Hoje encontramos grupos de pesquisa em polímeros em departamentos de Química Orgânica, de Físico-Química ou em Faculdades de Engenharia Química. Estes estão localizados em Porto Alegre, Campinas, São Carlos, Rio de Janeiro, Brasília, Salvador, Campina Grande e Fortaleza. Esta sub-área se confunde com a engenharia de materiais (reologia e processamento, por ex.), com a física (polímeros condutores e fotoresistes) e com a biologia e medicina (materiais poliméricos biocompativeis, por ex.), sendo essencialmente interdisciplinar.

Ressalta-se a destacada preocupação dos pesquisadores químicos com a deterioração do meio ambiente no ambito das investigações interdisciplinares, notadamente a Química Ambiental - que busca 0 entendimento da natureza e dos agentes nela intervenientes. Essa preocupação ocorre também em nível da sociedade civil e, por isso, tornou-se política e economicamente importante. Ela é ainda mais expressiva ao se constatar a ênfase dada às atividades de pesquisa que implicam em interação entre a Química e a Biologia: a Ecologia Química - onde a pesquisa busca contribuir, através do entendimento dos controles naturais, para a melhor sobrevivência do indivíduo no ecossistema [25].

\section{CONSIDERAÇÕES FINAIS}

As atividades da Pós-graduação em Química no Brasil têm sido fundamentalmente dirigidas à formação de recursos especializados e à criação de conhecimentos, de forma não articulada, por falta de uma política inicial privilegiando o desenvolvimento tecnológico endógeno.

Apesar da qualidade bastante razoável da Pós-graduação, o contingente de pessoas a ela dedicadas (577 docentes-doutores, em 1991) ainda é reduzido. Em muitos casos a sua inoperância é causada pela incapacidade de adaptar os projetos de pesquisa às condições dos laboratórios, em alguns casos, mais bem equipados do que alguns laboratórios europeus.

Não há dúvida de que a pesquisa brasileira em Química, apesar de sua modesta dimensão, tem bom nivel de qualidade em certas sub-áreas/especialidades, atestada, por exemplo, para as pesquisas de carácter mais básico, pela aceitação dos artigos pertinentes pelas revistas internacionais de primeira linha. Há que se considerar, também, a disparidade de seu desenvolvimento nas diferentes regiões do pais.

\section{REFERÊNCIAS}

1. C. A. L. Filgueiras, Quím. Nova 8 (1985) 263.

2. C. A. L. Filgueiras, Quim. Nova 9 (1986) 263.

3. C. A. L. Filgueiras, Quim. Nova 16 (1986) 155.

4. H. Rheinboldt, "A Química no Brasil", cap. VIII in As Ciências no Brasil, F. Azevedo (org.). Ed. Melhoramentos, São Paulo (1955).

5. S. Mathias, "Cem anos de Química no Brasil",
Colecção da Revista de História (LXIII), São Paulo (1975).

6. C. A. L. Filgueiras, Quím. Nova 11 (1988) 210.

7. S. Schwartzman, "Formaçāo da Comunidade Cientifica no Brasil", FINEP e Cia. Editora Nacional, Rio de Janeiro e São Paulo, 1979.

8. CAPES, Resultados da Avaliação da Pós- graduação por Área do Conhecimento 19791989, Brasilia, 1991

9. a) M.A.H. Cagnin, Quim. Nova 14 (1991) 219, b) M.A.H. Cagnin, Quím. Nova 16 (1993) 161 e c) M.A.H. Cagnin, Interciência 18 (1993) 146.

10. M.A.H. Cagnin, Quím. Nova 10 (1987) 223

11. Anais do 5th Brazilian Meeting on Organic Synthesis, Campinas, 1992

12. V. Walsh, Res. Policy 13 (1987) 211.

13. J. Feldman et al., Quím. Nova 12 (1989) 379.

14. C. Airoldi e A. P. Chagas, Quím. Nova 6 (1983) 13

15. M.A.H. Cagnin Rev. Bras. Tec. 18 (1987) 10 ,

16. A.C. Massabni et al., $13^{a}$ Reunião Anual da SBQ, Minas Gerais, 1990.

17. R.M. Baum, C \& EN 6 de Fevereiro (1989) 24

18. H.E. Toma, $13^{a}$ Reunião Anual da SBQ, Minas Gerais (1990).

19. S. Schwartzman, Formação da Comunidade Científica no Brasil, Cia Ed. Nacional/Finep, 1979.

20. M.A.H. Cagnin, Interciência 10 (1985) 64.

21. F.A.J.L. James, British J. Hist. Sci. 21 (1988) 181.

22. M. Riveros, Mimeo. (1993) 54

23. F. Galembeck et al., $13^{\sharp}$ Reunião Anual da SBQ, Minas Gerais, 1990

24. G. Whitesides, Angew. Chem. Int. Ed. Engl. 29 (1990) 1209

25. W.B. Mors, Interciência 13 (1988) 221.

* Instituto de Química da Universidade Estadual de Campinas.

** Universidade de Brasilia, Directora Adjunta da FLACSO-Sede Brasil (Convênio FLACSO/CNPq)

*** Instituto de Química da Universidade Estadual de Campinas, ex-Presidente da Sociedade Brasileira de Química (Maio 92/Maio 94).
37 